\title{
SOBRE LA DETERMINACIÓN SOCIAL DE LA RACIONALIDAD *
}

LEON OLIVÉ

UNIVERSIDAD AUTÓNOMA METROPOLITANA-IZTAPALAPA

Instituto De InVestigaciones Filosóficas

Universidad Nacional autónoma de México

En este trabajo me interesa discutir las nociones de racionalidad y de criterios de racionalidad desde una perspectiva relevante para la sociología de las creencias y del conocimiento, y en particular para el análisis de sociedades 'primitivas', especialmente en cuanto a sus sistemas y prácticas mágicas y religiosas.

El meollo de la cuestión es si la racionalidad y los criterios de racionalidad son universales, y si lo son, en qué sentido; o bien si dependen siempre de contextos socioculturales específicos, o incluso si dentro de un mismo contexto sociocultural son históricamente variables, y si coexisten de hecho racionalidades distintas. ${ }^{1}$

Aparte del interés que la cuestión de la racionalidad y de sus criterios presenta por sí misma, puede apreciarse sin dificultad que tiene importantes consecuencias para el trabajo sociológico y antropológico. Por ejemplo, ¿es posible justificar que los análisis de creencias, de acciones, de rituales, de prácticas, etc., requieren, además de explicación y de comprensión, una evaluación pretendidamente basada en criterios de racionalidad universales, es decir, criterios que se alega son independientes de todo contexto cultural y, por tanto, que permiten una evaluación justa y correcta?

Esto no es menospreciar las grandes dificultades que también presentan los problemas de explicación y de comprensión en las ciencias sociales. Lo que sugiero es simplemente que, en mi opinión, estos últimos

* Agradezco al Instituto de Investigaciones Filosóficas de la UNAM la invitación que me extendió para discutir una versión previa de este trabajo en su seminario de investigadores. El Dr. Mario Otero hizo la réplica, ofreciéndome valiosos comentarios y críticas.

1 Doy por sentado que las concepciones acerca de la racionalidad y sus criterios varian de un contexto socio-cultural a otro, y de un momento histórico a otro. Mi preocupación se centra en aquello a lo que se refiere el concepto de racionalidad y los de criterios de racionalidad. 
problemas se consideran con gran frecuencia contra un telón de fondo supuestamente incontrovertible, el cual a menudo incluye la noción de racionalidad y de los principios de racionalidad. $\mathrm{Y}$ es precisamente ese telón de fondo el que deseo poner en cuestión en este trabajo.

El problema al que aludo también tiene consecuencias importantes para el estudio de las ideologías en las sociedades industriales contemporáneas y para el análisis de las ciencias, como instituciones, como prácticas y como cuerpos sustantivos de conocimientos en esas sociedades. La pertinencia podrá apreciarse si se piensa en la posibilidad de distinguir entre ciencia e ideología con base en las pretensiones de racionalidad de la primera, si bien esto sería sólo uno entre varios factores para fundar la distinción. En cualquier caso, es muy importante determinar los elementos culturalmente dados en las ciencias y en general en las creencias. ¿Hasta dónde las pretensiones de racionalidad científica dependen de la herencia cultural peculiar de su contexto social?

En efecto, recientemente ha aumentado la disposición a aceptar que la racionalidad científica no está justificada en sus pretensiones de universalidad, y por tanto los patrones de racionalidad y de validez científicos no se erigen ya como medidas incontrovertibles para hacer evaluaciones de creencias y de acciones en el interior de nuestra sociedad y fuera de ella. En particular se discute que las ciencias no son obviamente sistemas de creencias y de acciones alternativas claramente superiores a la magia y las religiones, y que no es claro que se les pueda oponer a sistemas de creencias y de prácticas que se les tacha de ideologías. El status de la ciencia en nuestra sociedad se ve así seriamente afectado.

Más aún, se ha puesto en duda que los conocimientos científicos tengan un status epistemológico privilegiado. Tal es el interés de tendencias recientes en filosofía y sociología de la ciencia las cuales, a diferencia de corrientes tradicionales que han sostenido que el análisis sociológico puede ser útil para tratar problemas del origen, distribución, organización y transmisión de los conocimientos, pero nunca para discutir su validez, han convergido en la insistencia de dar cuenta de los conocimientos científicos sustantivos como productos de subculturas específicas - las comunidades científicas - de modo que tanto los problemas de validez como los de producción, aceptación y transmisión de conocimientos científicos admiten el mismo tratamiento que otros productos culturales cualesquiera.

En este trabajo no me comprometo a discutir todas esas consecuencias, ni siquiera superficialmente. Me pareció, sin embargo, conveniente dejar asentado que mi interés en la racionalidad y sus criterios surgió del papel clave que estas nociones desempeñan dentro de la problemática que he señalado. 
Comenzaré por la cuestión de si la racionalidad es universal. Como suele ocurrir con planteamientos de este estilo, la discusión parecería ociosa sin antes aclarar qué se entiende por uno y otro concepto: "racionalidad" y "universalidad". El trabajo analítico es importante y necesario para la problemática que me interesa. Parcialmente me ocuparé de él, pero por dos razones lo abandonaré antes de haberlo llevado a un nivel satisfactorio. La primera es una decisión metodológica, a saber, la conveniencia de pasar a problemas más urgentes desde mi perspectiva, los cuales es factible considerar aun con el análisis conceptual inconcluso. La segunda se refiere a un problema sustantivo de fondo: el análisis conceptual, desde una perspectiva filosófica, corre el riesgo de partir de ciertas concepciones, sin ponerlas a discusión, las cuales quedan en el centro mismo de la problemática que me interesa. Trataré de aclarar estas observaciones, al mismo tiempo que aprovecharé para iniciar la discusión, recurriendo a dos ejemplos, uno de un enfoque analítico, otro de uno sociológico. En el primer caso me referiré a un trabajo de Jesús Mosterín sobre el concepto de racionalidad. ${ }^{2}$ En el segundo tomaré unos trabajos de Steven Lukes sobre racionalidad y relativismo. ${ }^{3}$ Me permitiré citar con cierto detalle a estos autores con la intención de aclarar la noción de racionalidad que me interesa manejar en lo que sigue, así como para ilustrar el punto metodológico en cuestión: el de la diferencia de enfoque entre el análisis puramente conceptual y el de orientación sociológica.

Ciertamente, la noción de racionalidad que me preocupa, como se ha apreciado en los párrafos introductorios, es la que se predica de creencias, opiniones, acciones, decisiones y conductas de los seres humanos. ${ }^{4}$ Siguiendo a Mosterín, llamaré racionalidad creencial a la que se predica de opiniones y de creencias, y racionalidad práctica a la que se predica de acciones, decisiones y conductas. ${ }^{5}$

2 J. Mosterín, "El concepto de racionalidad" en Racionalidad y Acción Humana. Alianza Universidad, Madrid, 1978.

3 S. Lukes, "Some problems about rationality" en European Journal of Sociology, vol. 8 (1967).

-, "On the Social Determination of Truth" en Modes of Thought: Essays Presented to E.E. Evans-Pritchard, compilado por R. Horton y R. Finnegan. Faber, Londres, 1973.

-, "Relativism: Cognitive and Moral" en Supplementary Proceedings of the Aristotelian Society (1974).

Todos reimpresos en S. Lukes, Essays in Social Theory. Macmillan, Londres y Basingstoke, 1977. He tomado las citas de este volumen.

* Véase Mosterín, op. cit., pp. 16-18, para una breve discusión de varios significados de "racional".

5 Ibid., p. 18. 
Lukes se refiere también a este tipo de racionalidad. Caracteriza a una creencia como una proposición aceptada como verdadera y luego indica cinco maneras en que una creencia o un conjunto de creencias pueden ser irracionales: i) si son ilógicas, por ejemplo, si son internamente incoherentes o francamente contradictorias entre sí; ii) si son parcial o totalmente falsas; iii) si carecen de sentido (pero reconoce que entonces difícilmente pueden aceptarse como proposiciones y por tanto como creencias); iv) si son propuestas ad hoc, específicamente para una situación; v) si han sido aceptadas de maneras deficientes en algún sentido, por ejemplo: a) basadas sobre pruebas insuficientes, es decir, que el actor no estaría justificado en admitir que la proposición, o las proposiciones, son verdaderas, $b$ ) basadas sobre consideraciones que no vienen al caso, $c$ ) aceptadas de modo no crítico, sin prestar atención a sus supuestos e implicaciones (aunque Lukes reconoce que en este caso la irracionalidad debe predicarse del creyente, no de la creencia), $d$ ) aceptadas sin quedar sujetas a revisión ni modificación alguna bajo ninguna circunstancia, por ejemplo, se les puede considerar creencias 'sagradas' y protegerlas siempre ante potenciales pruebas que las refutaran. Luego especifica otros cinco sentidos en que el término 'racional' se aplica a las acciones de los seres humanos: vi) acción orientada hacia un fin; vii) la adopción de los medios de hecho más eficientes para conseguir un fin; viii) la adopción de los medios que el agente cree son los más eficientes para conseguir los fines que se plantea; $i x$ ) la ejecución de acciones que de hecho conducen a los fines últimos del actor, sean o no explícitamente reconocidos por él, y $x$ ) el hecho que los fines que tiene un agente son los que deberia tener. ${ }^{6}$

Por su parte Mosterín sostiene que la racionalidad creencial consiste en creer, es decir, aceptar como verdadera una proposición y en estar justificados en hacerlo. El problema se desplaza entonces a cuándo y cómo puede decirse que un actor está justificado en creer lo que expresa una cierta proposición. La racionalidad práctica la define así: "Diremos que un individuo $x$ es racional en su conducta si (1) $x$ tiene clara conciencia de sus fines, (2) $x$ conoce (en la medida de lo posible) los medios necesarios para conseguir esos fines, (3) en la medida en que puede, $x$ pone en obra los medios adecuados para conseguir los fines perseguidos, (4) en caso de conflicto entre fines de la misma línea y de diverso grado de proximidad, $x$ da preferencia a los fines posteriores y (5) los fines últimos de $x$ son compatibles entre sí." "

Me permití citar ampliamente a estos dos autores porque, como senalé antes, el contraste es ilustrativo. El autor más sociológicamente

6 lukes, op. cit., pp. 132-33.

7 Mosterin, op. cit., p. 30. 
inclinado hace un análisis insuficiente del concepto central, el de racionalidad. Para decir lo más inofensivo, esto le impide hacer un planteamiento más claro y limpio del problema. Como ejemplo del contraste indicaré que los modos $i$ ), ii) y iii) que apunta Lukes quedan englobados en el planteamiento de que una creencia es racional si el creyente está justificado eñ aceptar la proposición que la expresa como verdadera. Si la proposición es autocontradictoria, no existe justificación para aceptarla como verdadera; igualmente si es parcial o totalmente falsa (ésta es la condición ii) que señala Lukes). Pero aquí surge un problema que la formulación de Lukes no permite tratar claramente: ¿sabe el agente que es falsa? Diríamos que es irracional que la acepte como verdadera si pudiera comprobar que no lo es. Pero en la formulación de Lukes no se hace alusión a esto. Bajo la presentación de Mosterín, en cambio, se parte del supuesto que el actor está justificado en aceptarla como verdadera, y es eso lo que vuelve racional su creencia, aunque resulte que de hecho la proposición es falsa; de ello puede llegar a percatarse el agente posteriormente, en cuyo caso, para comportarse racionalmente deberá abandonar la creencia, pero es posible que nunca se entere que de hecho la proposición que creyó verdadera no lo es.

Vemos pues que la elucidación analítica es importante, y en nuestros ejemplos, la de Mosterín permite tratar con mayor claridad un punto que en el análisis de Lukes queda confuso. Sin embargo, al llevar adelante el análisis conceptual, al menos en la forma en que lo hace Mosterín, se tropieza con dificultades serias desde el punto de vista que me interesa, el cual, me permito recordar, está relacionado con problemas de teoría social, sociología de las creencias y de la ciencia.

Para subrayar esto, así como la diferencia de los enfoques y su distinta relevancia para mi proyecto, permítaseme señalar cómo Mosterín pasa a hablar del problema de la justificación de una creencia. Arriba señalé que la definición que él da de racionalidad desplaza el problema a lo que es estar justificado para admitir una proposición como verdadera. Él mismo reconoce el problema y lo ataca de frente. En resumen, propone que un ser humano $x$ cree racionalmente que $\phi$-donde $\phi$ denota una proposición cualquiera- "si y sólo si (1) $x$ cree que $\phi$ y (2) $x$ está justificado en creer que $\phi$, es decir $\phi$ es analítico, o $x$ puede comprobar directamente que $\phi, o \phi$ es una opinión científica vigente en el tiempo de $x$, o hay testimonios fiables de que $\phi$, o $\phi$ es deducible a partir de otras ideas $\beta_{1} \ldots \beta_{n}$ y $x$ está justificado en creer que $\beta_{1} \ldots \beta_{n}$ (está cláusula convierte a esta definición en recursiva) y además, (3) $x$ no es consciente de que $\phi$ esté en contradicción con ninguna otra de sus creencias". ${ }^{8}$ 
Este análisis supone como bien asentadas y no problemáticas las nociones de verdad, de analiticidad, de deducibilidad, de contradicción, y más aún, acepta sin crítica alguna la racionalidad científica y concede autoridad a las opiniones de las comunidades científicas. Desde el punto de vista que me interesa esto es hacer una petición de principio inadmisible. Cierto, lo que un análisis de este estilo señala con toda propiedad es la relación que existe entre los conceptos que acabo de mencionar, pero lo que me interesa es hasta dónde podemos suponer que esos conceptos, y no sólo el de racionalidad, son universales (si bien aún no elucidamos que significa 'universalidad' en este contexto). Hasta aquí he sugerido poner en duda la universalidad de la racionalidad, para lo cual comenzamos con la revisión de un par de propuestas acerca de la noción misma de racionalidad. Esto significa que considero como problemática esta noción, lo mismo que los conceptos lógicamente implicados por ella.

En cualquier caso, con lo dicho hasta aquí se puede apreciar la necesidad de transformar la pregunta central inicial en la siguiente: ¿son universales los conceptos de racionalidad, de verdad, de validez, etc., ${ }^{9}$ y lo son los criterios respectivos? 10

En este momento se cierra parcialmente un lazo, pues ahora se sugiere la necesidad de aclarar cada uno de los conceptos involucrados, lo mismo que sus relaciones, cosa que no haré. Tal vez valga la justificación de que cualquiera que sea el análisis conceptual que se desarrolle, supondrá elementos culturalmente dados (para nosotros). Y mi interés radica precisamente en discutir si esos elementos pueden considerarse presentes en toda sociedad y en toda cultura, pasada, contemporánea o futura. En mi opinión es lícito en este momento abandonar la discusión puramente analítica de los conceptos involucrados en torno a la noción de racionalidad, pues se ha visto que el riesgo es partir exactamente de lo que está en tela de juicio. Así, considero un movimiento metodológico apropiado pasar a examinar la cuestión de la universalidad de la racionalidad, de la validez, etc., a pesar de que el análisis conceptual queda inconcluso.

9 A qué se refiere el 'etc.' es algo que deberfa aclararse a través de un análisis de los conceptos. Aun cuando reconozco su necesidad, enseguida trato de dar una justificación para dejarlo de lado.

10 Aceptemos momentáneamente que se trata de criterios para determinar cuándo una proposición es verdadera, un razonamiento válido, una acción o una creencia racionales, etc. 
Ahora bien, reconozco que este paso no se puede dar sin una mínima aclaración conceptual acerca del término 'universalidad'. ¿Qué se quiere decir por universalidad de, digamos, la racionalidad? ¿Se quiere decir, por ejemplo, que es una característica de toda sociedad? ${ }^{11}$ Me parece que no habrá mucha dificultad en reconocer que notoriamente no sería ésa una buena noción de universalidad. Aun cuando no llegamos a ningún acuerdo sobre el significado de "racionalidad", la vaga noción que he manejado dejó claro que es algo que se predica de creencias, opiniones, acciones, decisiones, conductas, de los seres humanos. Análogamente, es posible añadir que se puede predicar de las creencias, acciones, etc., que se dan en una sociedad. Pero del mismo modo que bajo esos supuestos la racionalidad no es una facultad de los seres humanos qua individuos, tampoco lo es de las sociedades. Si no es una facultad de los individuos ni de las sociedades, ¿qué se querría decir al afirmar que la racionalidad es una característica de toda sociedad?

Bajo una definición como la de Mosterín, en el ensayo citado arriba, es posible definir lo que sería un individuo racional en sus creencias; podría darse una definición análoga para las sociedades. Mosterin da la siguiente definición: "Si un individuo cree de hecho todas y sólo las ideas en que le resulta racional creer, o al menos está siempre dispuesto a modificar su sistema de creencias en tal sentido, diremos de él que es racional en sus creencias." 12 Obviando la que me parece gran dificultad de recurrir a un término disposicional para dar la definición, pues en mi opinión la haría poco operacional si se intentase convertirla en un criterio efectivo para identificar sujetos racionales en sus creencias, hay que subrayar que la definición recalca la cuestión que de hecho el individuo en cuestión, o la sociedad en cuestión para el caso que más nos interesa, deben creer todas y sólo las ideas en que les es racional creer. Entonces se vuelve un problema empírico el de si todas las sociedades que existen, que han existido y que existirán, son, han sido y serán racionales en sus creencias, sin determinar lo cual no sería posible decidir sobre la universalidad de la racionalidad. Nótese que he manejado deliberadamente de un modo vago la noción de sociedad racional en sus creencias. ¿Significaría que todos sus miembros individuales son racionales según, por ejemplo, la definición de Mosterín? Me parece indiscutible que bajo esta definición hay al menos una sociedad que no es racio-

11 Véase, por ejemplo, Lukes, op. cit., p. 159, donde habla de condiciones de verdad, reglas de la lógica y criterios de racionalidad que son universalmente en tanto que "existen y son operativos dentro de todos los lenguajes y las culturas".

12 Mosterín, op. cit., p. 23. 
nal en sus creencias, a saber, la nuestra; y con esto se demostraría que la racionalidad no es universal. En este momento parece más conveniente rechazar la propuesta noción de universalidad. De hecho, sospecho que los defensores de la universalidad de la racionalidad tienen distintas y mejores propuestas y que, con cierta razón, considerarían caricaturesco el análisis esbozado en este párrafo.

Se pueden sugerir, por ahora, otras dos maneras de entender la universalidad. Una sería simplemente suponer que no depende de ningún contexto, sin comprometerse a nada más. Otra sería sugerir que la racionalidad es una condición de posibilidad de la vida social, si bien los seres humanos y las sociedades pueden no ajustarse estrictamente a ella, y hasta violarla sistemáticamente - aunque tal violación sistemática significaría que de hecho se presupone la racionalidad en este contexto. $¿$ Es sostenible alguna de estas posiciones, o alguna variación de ellas? Es conveniente prestar ahora atención a defensores de la universalidad de la racionalidad, ver qué proponen y cómo lo defienden.

Steven Lukes, por ejemplo, ha tratado de fundamentar, en los artículos que he señalado antes, la posición de que a nada conduce la tentación de creer que reglas y criterios que especifican lo que cuenta como verdadero y como razonamientos válidos son siempre relativos a grupos particulares, culturas o comunidades. Más aún, argumenta que 1) no hay buenas razones para suponer que todos los criterios de verdad, de validez y. de racionalidad son variables y dependientes de contextos, y 2) que hay buenas razones para suponer que algunos criterios son universales y fundamentales, de modo que los que sí dependen de contextos específicos también dependen de los primeros.

Keith Dixon ha intentado también mostrar que el solo hecho de plantearse una investigación sobre la acción humana presupone un principio universal de racionalidad. ${ }^{13}$ Peter Winch, aunque comprometido con un relativismo, llega a admitir una universalidad en la línea de la segunda sugerencia apuntada arriba. ${ }^{14}$

Me parece que en los trabajos de estos autores aparecen argumentos típicos sobre la problemática que me interesa, y que su discusión ayuda a esclarecer un poco la noción misma de universalidad, tanto como algunas de las dificultades aquí encerradas. Por esto me permitiré revisar con cierto detalle esos argumentos. Adelantaré que ninguno de los ar-

13 Keith Dixon, "Is Cultural Relativism Self-Refuting?" en The British Journal of Sociology, vol. xxviii, núm. 1 (marzo de 1977), pp. 75-88.

14 P. Winch, "Understanding a Primitive Society" en American Philosophical Quarterly 1 (1964), 307-24. Cito de la reimpresión en F. R. Dallmary y T. A. McCarthy (comps.), Understanding and Social Inquiry, University of Notre Dame Press, Notre Dame y Londres, 1977, pp. 159-88. 
gumentos de Lukes ni de Dixon, ni todos en conjunto, me parecen convincentes para aceptar la universalidad de la racionalidad, la validez, etc., ni de sus criterios. Pero de la discusión extraeré elementos que en mi opinión son muy útiles para conformar una idea más clara del problema central.

Lukes sostiene que autores como Mannheim, Lévy-Bruhl, Winch, Whorf y Kuhn, quienes se han preocupado por la diversidad del pensamiento humano según distintas coordenadas: posición social, cultura, lenguaje o paradigmas científicos, \mantienen en diferentes grados dos tipos básicos de argumentos. En primer lugar que, puesto que la percepción y la comprensión del mundo depende de teorías, entonces no hay referencias independientes de teorías para términos tales como 'mundo', 'naturaleza', 'realidad', etc., y por tanto no hay criterios de verdad que sean independientes de teorias. Igualmente, no hay criterios de validez que no sean variables, pues la noción de lo que constituye un paso válido de una proposición $p$ a otra $q$, también depende de teorías.

Ante esto, Lukes correctamente responde que una cosa es la influencia inevitable de las teorías sobre la percepción y la comprensión, y otra distinta que no haya objetos de percepción y comprensión independientes de las teorías. Análogamente, una cosa es la influencia de las teorías sobre lo que cuenta como válido y consistente, y otra que la validez y la consistencia sean dependientes de teorías.

En segundo lugar, Lukes se refiere a la posición defendida, por ejemplo, por Mannheim acerca de la variabilidad social de los cánones de verdad y de validez, en función de sus determinantes sociales. Lukes propone analizar el término 'determinación' como cualquier forma de relación explicativa, sea que se refiera a causas, a razones, a motivos, a propósitos, a aspiraciones o a intereses; y propone también que el término 'social' admita un rango de definiciones desde puramente materiales hasta culturales. Luego alega que según esas definiciones se puede admitir que todas las creencias sean socialmente determinadas, y no por ello concluir que la verdad, la validez, la coherencia y la racionalidad son relativas.

Hasta aquí sigo a Lukes. Sin embargo, él concluye que no existen razones satisfactorias para suponer que no hay criterios de verdad y de razonamiento válido invariables e independientes de todo contexto. Con esto no estoy de acuerdo. Lo que hizo ver Lukes es que puede haber determinación social de las creencias, que lo que cuenta como válido y como verdadero puede depender de un contexto, y que aun así que una creencia sea de hecho verdadera, o un razonamiento válido, no depende de ningún contexto; eso es, o no, un hecho, independientemente 
de lo que crean los actores para quienes la creencia o el razonamiento son relevantes. De aquí se sigue que lo que es la verdad, la validez y la racionalidad debe ser definido con independencia de contextos sociales.

$\mathrm{Al}$ respecto hay dos observaciones importantes. Primero, esos conceptos deben ser definidos en algún lenguaje, inserto en algún contexto, por lo cual no es claro aún que de ahí se obtenga universalidad; o visto de otro modo, sugiere que por universalidad debe entenderse posibilidad de definición sin aludir en ella misma a un contexto especifico, pero admitiendo siempre que la definición sí queda constreñida por su propio contexto. Habría que explorar las consecuencias de esto. En segundo lugar, hay que subrayar que una cosa es definir lo que significa que una proposición cualquiera sea verdadera, y otra mostrar que alguna proposición específica lo es. Para esto es que se requieren los criterios de verdad. De aquí que desde el principio haya insistido en la importancia de la distinción entre racionalidad, por ejemplo, y criterios de racionalidad, es decir, los criterios bajo los cuales se decide si algo es o no racional. Según el argumento de Lukes es posible admitir una cierta universalidad de la validez, de la verdad, de la racionalidad, pero de ahí no se sigue que los criterios bajo los cuales se decide cuándo se está ante una instancia de proposición verdadera, de razonamiento válido o de acción racional, sean igualmente universales. En el trabajo de Lukes no siempre queda clara la distinción. Así, contra su pretensión expresada en 1) y 2) (ver arriba, p. 134), no ha mostrado que no hay buenas razones para suponer que los criterios de verdad y de validez dependen de contextos, ni que existen buenas razones para suponer que hay criterios universales y fundamentales.

En otro lugar, Lukes sostiene que una condición necesaria para tener éxito en la comunicación con miembros de otra cultura es que tengan "nuestra distinción entre verdad y falsedad". De no ser así "seríamos' incapaces de concordar aun acerca de lo que cuenta como la identificación exitosa de objetos públicos (localizados espacio-temporalmente)".15 Me parece que este argumento se sostiene sólo en la medida en que la verdad se identifique con un criterio pragmático de éxito o fracaso. Supongamos que nos encontramos frente a miembros de una cultura que nunca ha llegado a elaborar teorías de la verdad como las que se han construido en la nuestra. Más aún, que un escrupuloso trabajo antropológico nos permite suponer que no cuentan con un concepto de verdad que sea otra cosa que una representación de procesos verificativos o falsificantes. Con eso bastaría para ponerse de acuerdo con ellos acerca de, por ejemplo, la localización de esta montaña, este río, esta al- 
dea. Lo que debemos suponer es la existencia de un criterio verificativo que pone de manifiesto el éxito o fracaso de una acción ejecutada con base en una creencia. "¿Dónde está el río? Si caminas doscientos pasos en dirección a la montaña más alta lo encontrarás detrás de la hilera de sauces." ¿Por qué asumir que tal cultura debe tener una concepción de verdad, o criterios que rebasen este nivel, si con ello basta para concordar sobre la localización de objetos que le son indispensables? Más aún, con base en esos elementales criterios es posible la comunicación exitosa con miembros de culturas ajenas. Ahora bien, es dudoso que las diversas maneras en que en nuestra sociedad, por ejemplo en discusiones científicas, se presupone la noción de verdad, se reduzcan a procedimientos verificativos de ese estilo. Luego, el argumento de Lukes no parece concluyente.

Pienso, sin embargo, que hay un elemento valioso en esa idea, a saber, que las operaciones de verificación y de falsificación son realmente universales, ${ }^{16}$ en el sentido de que deben existir en toda sociedad como condición de posibilidad de su supervivencia. Si no hay una creencia de que el río se encuentra rumbo a la montaña, y si no se refuerza o se modifica la creencia con base en intentos repetidos en los que se verifica o falsifica la creencia, entonces difícilmente sobreviviría la aldea "primitiva" del ejemplo, suponiendo que no tiene otro suministro de agua. Pero, aceptando todo esto, sigue en pie la dificultad de que en sociedades complejas, como la nuestra, la vida social seguramente presupone diversas concepciones de verdad, falsedad, validez, racionalidad, etc., de modo que se incluyen criterios más sofisticados que los sugeridos en el ejemplo. Aunque volveré sobre el punto, quisiera adelantar que una de mis conclusiones será reconocer que hay rasgos que toda sociedad debe suponer y satisfacer - lo cual incluso puede defenderse por argumento y no es necesariamente un problema de determinación empírica. Ante eso, la alternativa será entre llamarle racionalidad, si conviene, a uno de esos rasgos, o aceptar que entre lo que sea que tienen en común todas las sociedades no hay nada que pueda llamarse racionalidad, ni criterios de racionalidad, pues quizá aceptar lo contrario nos llevaría a contravenir nuestras más arraigadas concepciones de lo que es racional, esto es, las nociones tal como son elaboradas por discursos sociológicos y filosóficos de nuestra sociedad.

Agregaré aquí que Lukes sugiere que la universalidad de criterios significa que existen y son operativos dentro de todo lenguaje y toda cultura. Con esto se compromete a que de hecho deben existir en toda

16 En otro pasaje (op. cit., p. 159), Lukes hace comentarios que sugicren esto de modo más explícito. 
sociedad como criterios. Me parece algo muy discutible. No puedo conciliar eso con el caso - concebible — de una sociedad ajena a la nuestra, donde nosotros identificáramos una desviación y un quebrantamiento sistemático de los supuestos criterios. ¿Por qué suponer que de hecho existen esos criterios en esa sociedad, si nunca ha habido ahi una acción o una creencia que se ajuste a ellos? Otra cosa distinta es que dentro de las potencialidades de los miembros de esa cultura, simplemente por ser seres humanos, exista la facultad de llegar a comprendernos y reconocer, después de una prolongada interacción con nosotros, que sistemáticamente han violado una norma o un criterio que nosotros les proponemos y que han llegado a entender. Pero entonces cabe la duda de si los individuos que comprendieran eso siguen siendo miembros representativos de su cultura, o si precisamente el hecho de comprender la regla o el criterio que les proponemos y aceptar que se han desviado, significa que se han aculturado a nuestra sociedad. La medida en que eso afectara a su sociedad dependería, supongo, del grado de interacción entre la nuestra y la de ellos. Por ejemplo, debe ser muy distinto el efecto de un misionero aislado en una aldea recóndita de la selva amazónica, al efecto de la colonización española en América. Hay algo en esta idea que me produce incomodidad. ¿Habría que aceptar ciertas potencialidades en los seres humanos, tales que posiblemente todos llegarían a sujetarse a nuestra racionalidad y sus criterios? Tal vez el meollo de la universalidad de la racionalidad radica en esa potencialidad. Pero aun si así fuera, no veo por qué aceptar como suprema la racionalidad presupuesta por la filosofía y la sociología de nuestra sociedad. El mismo argumento se aplicaría al revés. Potencialmente todos los seres humanos podríamos quedar sujetos a la racionalidad presupuesta por otra cultura. Pero en esta línea de pensamiento, ¿qué tan decisivo sería el hecho de que el mundo industrializado se ha convertido en el dominante, y que en ese mundo prevalecen la racionalidad y los principios lógicos que, de un modo más o menos correcto, recogen las concepciones dominantes al respecto en las discusiones sociológicas y filosóficas? No estoy preparado por ahora para abordar estas cuestiones.

Otro argumento que avanza Lukes es una variación de algo que vimos arriba. La mera actividad social, la existencia, supervivencia y reproducción de una sociedad, nos permite suponer que hay una realidad independiente de las concepciones que en esa sociedad haya acerca de ella misma y de su entorno. El principio de este argumento me parece correcto. ${ }^{17}$ Pero Lukes no especifica por qué del establecimiento de una

17 Es la idea básica para reconstruir una ontología realista para la ciencia. Véase, por ejemplo, R. Bhaskar, A Realist Theory of Science. Harvester Press, Londres, 1978. 
ontologia realista (sea para la ciencia, sea para sistemas conceptuales de comunidades cualesquiera), se sigue que hay criterios de racionalidad y de validez universales.

Finalmente, Lukes sostiene, siguiendo en esto a Martin Hollis, que cualquier lenguaje debe contar con reglas lógicas, y propone de hecho que el concepto de negación y los principios de identidad y de no contradicción deben operar en todo lenguaje. De no ser así, prosigue retóricamente, ¿podrían los miembros de otra sociedad "ser acreditados con la posibilidad de inferir, argumentar y aún de pensar?" 18 Lukes no desarrolla más este argumento. Le parece quizá que por sí mismo tiene gran fuerza. Por mi parte no comparto esa opinión. Pensar no es necesariamente construir argumentos deductivos correctos. El mismo Lukes asegura en otro lado: "cualquier cultura, científica o no, que se comprometa a hacer predicciones exitosas (y es difícil ver cómo sobreviviría una sociedad que no lo hiciera) debe presuponer una realidad dada". ${ }^{19} \mathrm{Me}$ interesa destacar que parece ser necesario acreditar, a cualquier sociedad humana que sobreviva cierto periodo, con la capacidad de hacer ciertas predicciones exitosas. A su vez, eso presupone que pueden hacer inferencias inductivas. Así pues, habrá que reconocer que sus miembros piensan e infieren, pero no por ello hay que suponer que en su discurso operan los principios lógicos que Lukes señala; para ello debería mostrar que toda inferencia inductiva presupone tales principios lógicos.

Con base en lo anterior se puede concluir que Lukes no presenta buenos argumentos, ni buenas razones, para suponer que hay criterios de verdad, de validez y de racionalidad, universales y fundamentales.

\section{IV}

Comentaré ahora algunos de los argumentos de Dixon. Este autor propone que toda explicación de acciones y de creencias tiene dos elementos: uno de procedimiento y uno sustantivo. El primero se refiere a que en todo discurso, especialmente en los que pretenden dar explicaciones, hay presupuesta una norma de inteligibilidad, es decir, el hablante se propone hacer su discurso inteligible para sus interlocutores. Ahora bien, conforme se desarrolla una interacción comunicativa se debe dotar de contenido a ese compromiso normativo inicial. A esto se refiere el elemento sustantivo presupuesto por el discurso. Admito esta propuesta y me parece que ciertamente señala dos rasgos universales, es decir, nece- 
sariamente presupuestos por todo acto de habla o intento comunicativo, y por tanto por toda sociedad. Ahora bien, Dixon sugiere que la racionalidad se refiere a ese doble presupuesto de toda acción comunicativa. Con esto inicia un paso en falso que se completa al proponer que el sociólogo y el antropólogo presuponen que toda acción social puede ser vista como inteligible. Con esto estoy de acuerdo, y no es lo que marca el paso en falso. El problema surge cuando asegura que el proceso de hacer inteligible una acción involucra un detallado escrutinio de la conducta real, tanto para extraer los presupuestos sustantivos de los actores dentro de su cultura, como para evaluar si son relevantes para la acción. ${ }^{20}$

No pongo en duda que esta versión dé cuenta de un aspecto del trabajo antropológico y sociológico. Lo que no acepto es basarse en esto para aducir universalidad del criterio de racionalidad. Dixon mismo ha puesto los límites de lo que se refiere. De presupuestos universales de todo acto comunicativo, pasó al trabajo de sociólogos y antropólogos, agentes característicos de nuestra cultura. No hay razón para pensar que esa evaluación que podemos admitir como necesaria e indispensable para el trabajo científico social corresponda a un rasgo característico de la racionalidad, y menos que la haga universal.

Dejaré de lado otros comentarios de este autor, pues lo que me interesa recoger ya ha sido planteado: la necesidad de reconocer que el concepto de explicación, cuando se aplica a acciones humanas y a creencias, presupone un marco categorial en el contexto de lo que se quiere explicar. La contribución importante del escrito de Dixon es, para mí, aclarar que "el concepto de racionalidad es una forma categorial cuya sustancia es esencialmente debatible [essentially contestable]". ${ }^{21}$ Ahora bien, dentro de su posición nada muestra que tenga que haber algún conjunto especifico de categorías que sustantivicen esos marcos, y que necesariamente sean presupuestas por toda sociedad.

Con base en lo dicho hasta aquí, quisiera extraer una conclusión parcial. Conceptos como los de verdad, validez, corrección, racionalidad, aluden a marcos categoriales presupuestos por toda acción e interacción social. Esos marcos se sustantivizan en contextos culturales específicos acompañados necesariamente de criterios de identificación, según los cuales es posible decidir el apego o conformidad, o bien el quebrantamiento de la norma en cuestión, la racionalidad o irracionalidad de la acción, etc., si bien los actores pueden no estar conscientes de todos los criterios. Los criterios son siempre dependientes de un contexto, lo cual 
no veo que tenga que impedir que puedan ser identificados y resultar inteligibles para miembros de otras culturas. De lo que se puede predicar universalidad es, entonces, de la necesidad de cierto tipo de categorías, y también de la necesidad de que vayan acompañadas de ciertos criterios de decisión. Pero la forma en que se sustantivizan los conceptos y los criterios depende de cada contexto. Es importante no perder de vista que cuando se hace atribución de alguno de estos conceptos, necesariamente se hace desde una perspectiva particular, dentro de marcos conceptuales específicos. Finalmente, creo que en nuestra sociedad con frecuencia se quiere incluir dentro de la noción de universalidad la posibilidad de evaluar creencias, prácticas y acciones de otras culturas alegando la independencia contextual de esos conceptos.

\section{V}

Recordaré que me interesa el concepto de racionalidad desde la perspectiva en que se ha usado para justificar una superioridad de la ciencia sobre sistemas alternativos, mágicos o religiosos, por ejemplo. $\mathrm{Al}$ respecto Peter Winch ha hecho una sugerencia importante. ${ }^{22} \mathrm{Si}$ se comparan sistemas de ese tipo al interior de nuestra sociedad, donde están en competencia con la ciencia, por ejemplo, entonces es válido aplicar criterios de unos a otros, y hasta recurrir a criterios externos con respecto a cada uno de ellos, pero internos al fin y al cabo del mismo contexto socio-cultural. Pero si se trata de comprender una cultura distinta, entonces es inadmisible pasar al plano evaluativo que asume una superioridad de los juicios explicativos del observador sobre los de los actores. En uno y otro caso los conceptos de racionalidad involucrados son distintos.

Hay, sin embargo, un sentido en el cual Winch está dispuesto a admitir la universalidad de la racionalidad. Toda sociedad debe tener un cierto concepto de racionalidad, lo cual no es decir que todas las sociedades deben tener el mismo concepto de racionalidad. El meollo de su argumento es que "donde hay un lenguaje, lo que se dice debe hacer una diferencia y esto es posible sólo donde al decir una cosa se excluye otra, bajo pena de fracasar en la comunicación". ${ }^{23}$ A final de cuentas la argumentación llega a que debe haber normas y conformidad o quebrantamiento de ellas. Qué cuenta como norma, y qué como conformidad, es algo culturalmente variable. Lo invariable es que debe haber algo

22 Winch, op. cit.

23 Ibid., p. 177. 
análogo a nuestras normas y a nuestra noción de conformidad y de quebrantamiento.

En la cita del párrafo anterior, el problema central es que lo que se dice en un lenguaje debe producir una diferencia dentro del estado de cosas vigente. Entiendo esto como recurso a la noción de comunicación exitosa. Entonces, lo que se señala como presupuesto universal es realmente la posibilidad de comunicación exitosa, y no encuentro nada en el argumento de Winch que nos obligue a aceptar que lo que es universalmente presupuesto es la racionalidad -a menos, claro, que esta última se reduzca a la primera.

Se apreciará que la línea de argumentación de Winch conduce hacia donde ya hemos apuntado desde otras direcciones: hay ciertos presupuestos existenciales de toda vida social. $O$ bien se reduce la racionalidad a alguno de esos aspectos (suponiendo que un acuerdo es posible al respecto), o bien se admite que la racionalidad, en los diversos modos como es concebible y de hecho concebida y presupuesta en nuestra sociedad, no es universal. Optar por una u otra posibilidad lleva a la adopción de versiones distintas de lo que es la racionalidad. Esto entraña una dificultad que no me parece despreciable. Desarrollaré brevemente este punto, lo cual permitirá expresar claramente las opciones que en mi opinión quedan abiertas para tratar el problema de la universalidad de la racionalidad y de los elementos con los cuales está relacionada.

Al principio de este trabajo me detuve en una formulación reciente de Mosterín, la cual creo que recoge aceptablemente una serie de elementos que en nuestra sociedad y en nuestra época se incluyen en la noción de racionalidad. Para el punto que me interesa, conviene hacer notar que su versión de racionalidad práctica no es muy distinta de, por ejemplo, la definición de racionalidad instrumental que da Parsons: "la acción es racional en la medida en que persigue fines posibles dentro de las condiciones de la situación, y por los medios que, entre los disponibles para el actor, resultan más adaptados intrínsecamente al fin, por razones comprensibles $y$ verificables por la ciencia empírica positiva". ${ }^{24}$

Entre otros problemas que plantea, se puede decir que esta versión, igual que la de Mosterín, acepta como dado lo que me interesa poner a discusión, por ejemplo, la racionalidad científica. Pero no es esto lo que quiero discutir ahora, sino más bien subrayar que, desde un punto de vista filosófico como el de Mosterín, o uno sociológico como el de Parsons - ambos productos típicos de nuestra cultura - es prácticamente imposible tratar de reconstruir el concepto de racionalidad sin incluir los elementos que ellos mencionan, y esto porque es muy probable que

24 Talcott Parsons, La estructura de la acción social. Ediciones Guadarrama, Madrid, 1968, p. 98. 
en nuestra sociedad las acciones y creencias racionales sean efectivamente parecidas a lo que ellos proponen.

Ahora bien, para destacar la diferencia de una y otra de las alternativas mencionadas arriba sugeriré el ejemplo de una sociedad que me parece perfectamente concebible, donde nunca se den acciones racionales según el concepto de Mosterín o el de Parsons. Sin embargo esa sociedad podría sobrevivir, incluso por un largo periodo. No sería el caso, en cambio, con una sociedad que nunca fuera racional según el sentido que sugiere Winch. En su sentido, o se actúa racionalmente (esto es, hay normas y conformidad o inconformidad con ellas), o no hay comunicación exitosa y por tanto la sociedad no perdura.

Con lo dicho hasta aquí me permitiré apuntar otra conclusión parcial. Parece conveniente interpretar el término 'universalidad' como involucrando existencia en toda sociedad, en el sentido de ser presupuesto o condición de posibilidad de toda acción o interacción social. Si se adopta este punto de vista, entonces un ejemplo como el sugerido en el párrafo anterior mostraría que la racionalidad, tal como suele ser definida por tendencias importantes en filosofía y en teoría social dentro de nuestra sociedad, no tiene por qué suponerse universal. Ante esto, una alternativa es contravenir la opinión prevaleciente de la filosofía y sociología contemporáneas, proponer que racionalidad es otra cosa que lo que ahí se define y defender una versión que factiblemente aparezca como universal —entiendo que, en términos generales, ésta es la estrategia de Winch en el artículo citado. Claro está que estas alternativas no son mutuamente excluyentes, bajo la condición de renunciar a llamarle racionalidad a lo que se proponga como presupuesto de toda acción social. Esto es, se puede admitir que, si bien no hay consenso filosófico ni sociológico sobre lo que es la racionalidad, y de hecho hay mucho por hacer en cuanto a la elucidación conceptual, en cualquier caso las discusiones hasta ahora muestran que, sea lo que sea lo que es racional y lo que es la racionalidad en nuestro contexto sociocultural, incluyen rasgos que no tienen por qué suponerse universales, es decir, presupuestos por toda interacción social. Desde esta posición, entonces, se rechazaría la universalidad de la racionalidad, pero se apresuraría a insistir en que hay rasgos universales, comunes a toda sociedad, y que quizá algunos de ellos son prerrequisitos de nuestra racionalidad, por ejemplo, procesos verificativos, lo cual daría pie para pensar que aspectos de otras sociedades construidos sobre la base de esos prerrequisitos son, o funcionan, como análogos a nuestra racionalidad, aunque en sentido estricto sean diferentes. Mi simpatía personal está con esta posición. 
De esta última posición, junto con otros cabos que han ido quedando sueltos a lo largo del trabajo, se sigue que un rasgo necesario de toda explicación sociológica es que debe construirse y tiene sentido dentro de los marcos internos de culturas específicas. Ahora bien, es precisamente bajo esta formulación que autores como Dixon definen al relativismo cultural. ${ }^{25}$ Dado que mi posición me ha llevado a asumir, voluntariamente o no, una formulación de relativismo cultural, quisiera ahora prestar atención al problema de su coherencia interna.

Para ello me apoyaré en el artículo de Dixon ya mencionado, pues ahí señala tres variaciones del argumento contra el relativismo cultural que trata de mostrar que éste se refuta a sí mismo.

La primera variación reza así. El investigador relativista ofrece explicaciones, las cuales deberían ser evaluadas conforme a su coherencia lógica, su aproximación a situaciones y estados de cosas que describen (verdad), o por recurso a un criterio de racionalidad. Su posición es, sin embargo, que los conceptos de lógica y de principios lógicos, de verdad y de racionalidad son relativos a formas de vida, a contextos socioculturales. ¿Cómo es posible entonces someter a prueba sus explicaciones, bajo cuáles criterios habrá que juzgar su corrección? La acusación contra el relativista es que niega criterios intersubjetivos para verificar la explicación, pero ésta sólo tiene fuerza en la medida en que puede ser sometida a determinados criterios; por consiguiente, sus explicaciones carecen de fuerza.

Me parecería que esta objeción podría ser descartada sin más trámite por errar el blanco. En todo caso, como lo señala el mismo Dixon, una cosa es negar universalidad a los criterios y otra, que no se sigue de la anterior, decir que no hay criterios negociables intersubjetivamente según los cuales evaluar las explicaciones propuestas por el investigador. Lo único que el relativista sostiene es que esos criterios son internos a su propia cultura. $\mathrm{Y}$ es posible añadir que el mero hecho de requerir una explicación y de ofrecerla tiene sentido sólo en tanto que se propone y se ofrece dentro de un medio cultural (lo cual sigue siendo válido aún en el caso en que el interesado sea sólo el individuo que propone la explicación, pues él es producto de una cultura).

La segunda variación es una forma de refutación pragmática. Depende de si el investigador aduce cierto tipo de argumentos, los cuales pueden resultar incongruentes con el relativismo. Por ejemplo, ante rituales determinados, un antropólogo puede proponer que, además de los sig- 
nificados que esos rituales tienen en su contexto social para los miembros actores dentro de él, tienen la función de promover armonía entre grupos de parientes, es decir, de fortalecer la cohesión social. Así, podría acusarse al investigador de asumir que los rituales son en sí mismos ininteligibles, o que los participantes en los rituales tienen una falsa concienciá. Puesto qué eñ lá práctica atribuye a los actores o bien irracionalidad, o bien falsa conciencia, requiere el investigador de un criterio de racionalidad externo al medio que investiga, por referencia al cual justificar su atribución; pero ese criterio externo es el que niega por principio. Al respecto Dixon comenta que si se da, la incongruencia no se deriva per se de la posición relativista. Esto es cierto, pero se puede añadir que lo que se señala como incongruencia no es obviamente tal. Independientemente de los problemas que presente una explicación funcionalista, si un antropólogo recurre a ella, es cierto que requiere un criterio de racionalidad externo a la cultura que analiza, pero de ahí no se sigue que tenga que ser universal. Podría reconocer el antropólogo que el criterio presupuesto por su explicación depende de su cultura, y sin embargo justificar su introducción simplemente porque su intención es hacer inteligible precisamente a esa cultura la situación que estudia. Reconozco que este movimiento no sería bienvenido por un funcionalista prototípico, pero creo que en cualquier caso cumple su misión de defender al relativismo cultural contra el cargo de incoherencia.

Cierto, con lo anterior no se superan todas las dificultades encerradas en la objeción. Subsiste el problema de la atribución de falsa conciencia a los actores y de función latente a la institución, en la medida en que el observador tenga una pretensión de objetividad, en el sentido de que la función de la institución es un proceso real en la sociedad $x$; es decir, una realidad externa al observador y a su medio cultural, función de la cual, además, se asegura que los actores inmersos en esa sociedad no tienen conciencia. Al respecto quisiera señalar que los conceptos de "función latente" y de "falsa conciencia" son construidos y dependen, qua conceptos, de nuestro marco cultural, o de cualquiera que sea el contexto cultural desde donde se propone la explicación sociológica. Pero sus referentes, la función de la institución en la sociedad $x$ y la falsa conciencia de los actores en ella, no dependen de nuestro contexto. Ahora bien, en mi opinión, el problema serio que confronta una atribución de este estilo es el de probar que es correcta. La prueba de que de hecho hay falsa conciencia será distinta dentro del contexto cultural del observador, de la requerida para convencer a alguno o algunos de los participantes en la cultura observada. En el primer caso deberá ajustarse a los patrones de la cultura del observador -0 incluso de su sub- 
cultura, por ejemplo, la sociológica. Pero si el caso es dar una prueba para actores involucrados, entonces se trata realmente de una interacción transcultural y quizá de un proceso emancipatorio (en tanto que se intenta superar una falsa conciencia). En el primer caso no veo conflicto alguno en que se recurra a criterios que después de todo son interiores y dependen del contexto del investigador, pues son externos al contexto investigado. El segundo sí parece requerir un criterio culturalmente neutral, de otro modo el proceso se reduce a que el participante convencido de que tenía falsa conciencia es aculturado por el observador que lo "ilustró". Pero no hay nada en lo dicho que conduzca a la conclusión de que el patrón neutral respecto de las culturas que interactúan tenga que ser uno de racionalidad. Por otro lado, como la posición relativista que favorezco en este trabajo admite la existencia de rasgos universales, presupuestos de toda interacción social, se puede suponer que el patrón culturalmente neutral se hallará entre esos presupuestos, con lo cual queda salvaguardada la coherencia de la posición relativista contra la objeción hasta aquí discutida.

La tercera variación que menciona Dixon se refiere a una autorrefutación lógica del estilo de la paradoja del mentiroso. Supongamos que se enuncia la proposición "no hay proposiciones verdaderas" y se pretende que ésta sí lo es. Se quiere colocar al relativismo cultural en una posición análoga en tanto que sostiene la siguiente proposición: "todas las proposiciones verdaderas son culturalmente relativas". El relativista debe admitir que, si su proposición es verdadera, lo es sólo con respecto a su medio cultural. Pero esto no es realmente paradójico. Lo que sostiene el relativista es que la verdad de cualquier proposición es relativa en el sentido de que sólo puede ser mostrada y reconocida en ciertos contextos y por recurso a criterios que dependen de esos medios. En particular, la verdad de su proposición sólo puede ser mostrada y reconocida en su medio, por recurso a criterios específicos de él. Y esto no es incongruente con aceptar que lo que significa que una proposición sea verdadera, en particular la suya, pueda definirse en un lenguaje dado de modo tal que la definición no exija condiciones relativas a un contexto. El crítico lo acusa de no reconocer esto, cosa en la que está errado. En mi opinión, el punto del relativismo cultural es que lo que hay de socialmente significativo alrededor de la verdad de las proposiciones es que éstas existen en tanto que hay agentes que las producen, mantienen y creen, o no, que son verdaderas; y puede ser socialmente importante probar esa pretensión. Lo que queda relativizado a contextos sociales son, entonces, las pruebas mismas y los criterios que involucran.

Una variación de la anterior objeción, y una respuesta clara, han sido expresadas por David Bloor, desde una perspectiva que vale la pena 
mencionar aquí. En efecto, este autor defiende el llamado "programa fuerte" en sociología del conocimiento. ${ }^{26}$ Este programa conduce también a un relativismo cultural. Por ello, el autor se defiende contra el cargo de autorrefutación y apunta que la objeción presenta las cosas como si el relativista sostuviera que toda proposición y todo conocimiento, por ser socialmente determinados, no pueden ser verdaderos, y el problema surge porque esa tesis, por un lado, se propone como verdadera, pero al mismo tiempo tiene que ser reconocida como socialmente determinada, bajo pena de inconsecuencia lógica, y por tanto como falsa. Así, la objeción sería correcta contra quienes sostuvieran que determinación social implica falsedad. Pero no hay nada en el relativismo al que conduce el programa fuerte, ni en el que asumo aquí, ni siquiera en uno como el que defiende Winch, que conduzca a la idea de que determinación social implica falsedad.

Creo que no es por demás insistir en la defensa del relativismo señalando que, si bien los criterios a los que recurra deben ser reconocidos como relativos a su contexto social, no por ello deja de mostrar su validez si se ajusta a ellos; claro que muestra su validez sólo en ese contexto, pero eso es lo que importa. Una posición como la del "programa fuerte" nunca podría mostrarse como universalmente válida. Pero eso no le importa ni le afecta, si por universalidad se entiende abstracción en el espacio y en el tiempo (es decir, fuera de contextos históricosociales específicos), ya que para el programa fuerte, tanto como para el relativismo al cual deseo adherirme, no tiene sentido la idea de que hay creencias, conocimiento o proposiciones fuera de contextos sociales particulares.

Es posible concluir, entonces, que el relativismo cultural no es una posición que obviamente se refute a sí misma, o que de modo inmediato se enrede en incoherencias fundamentales.

\footnotetext{
26 David Bloor, Knowledge and Social Imagery. Routledge and Kegan Paul, Londres, 1976.

El "programa fuerte" es concisamente presentado así: la sociología del conocimiento "l) debería ser causal, esto es, preocuparse por las condiciones que hacen surgir creencias o estados de conocimiento. Naturalmente, habrá otro tipo de causas, aparte de las sociales, que cooperan para hacer surgir una creencia. 2) Debería ser imparcial con respecto a la verdad o falsedad, racionalidad o irracionalidad, éxito o fracaso. Ambos lados de estas dicotomías requieren explicaciones. 3) Debería ser simétrica en su estilo de explicación. El mismo tipo de causas explicarían, digamos, creencias verdaderas y creencias falsas. 4) Debería ser reflexiva. En principio, sus patrones de explicación tendrían que ser aplicables a la misma sociología." (pp. 4-5).
} 
A lo largo de este trabajo he dejado conclusiones parciales que ahora deseo recapitular.

Toda sociedad presupone como posibilidad de existencia ciertos marcos categoriales. En nuestra sociedad, algunas de las formas de esos marcos son llenadas por lo que llamamos racionalidad, validez, corrección, etc. Algunas formas son llenadas por los mismos contenidos en toda sociedad; por ejemplo, por criterios de verificación o de falsificación, por procedimientos para poner en evidencia el exito o fracaso de ciertas acciones, incluyendo procesos comunicativos.

Por universalidad legítima entiendo la que se refiera a esas formas, es decir, universalidad que se refiere a lo que toda sociedad debe presuponer para existir, sobrevivir y reproducirse.

Hay otra noción de universalidad, la cual, en mi opinión, es espuria porque a fin de cuentas depende de un contexto dado, pero es indispensable; la denotaré por el término " 'universalidad' ". La 'universalidad' se refiere a conceptos y categorías que desde un cierto contexto se pueden aplicar a toda creencia o acción que se pueda identificar en cualquier sociedad.

Sospecho que hay intereses, dentro de sociedades como la nuestra (los que se han manifestado en las muchas formas de etnocentrismo, por ejemplo), que pugnan porque se interprete la 'universalidad' como universalidad. Esto es, que se entienda que la aplicación de categorías y conceptos válidos en un cierto contexto, a cualquier acción o creencia de cualquier sociedad, es posible porque en ese contexto sí se cuenta con los criterios universales (sin más), y echar así un velo sobre la cuestión de que no es lo mismo aplicar categorías que dependen de ese contexto a toda sociedad, que creer que esas categorías no dependen de ningún contexto.

Ahora bien, en sociedades como la nuestra, ciertos criterios permiten proponer, desde marcos conceptuales específicos, lo que es racionalidad, verdad, coherencia, etc. Esto permite, a la vez, pensar que en otros contextos las proposiciones serán verdaderas o falsas, los razonamientos válidos o no, los discursos coherentes o incoherentes, las creencias y acciones racionales o irracionales —según esos criterios - independientemente de lo que crean los actores involucrados. Según una cierta noción de 'universalidad' queda el recurso de imaginar, de suponer contrafactualmente, que las atribuciones que los observadores hacen de verdad, racionalidad, etc., describen una realidad que de hecho es así y que existiria de esa manera independientemente de las acciones cognoscitivas de los sujetos inmersos en ese contexto y de las atribuciones correspondientes 
que ellos hagan a sus creencias y acciones. Así, la 'universalidad' está asociada a la posibilidad de sostener contrafactuales, los cuales son relevantes para los actores observadores que los hacen, no para el contexto observado en cuestión. ${ }^{27}$ En cada contexto lo que importa es la decisión de hecho -es decir, no contrafactual- de si una acción o una creencia es o no racional; y tal decisión es considerada y tomada según criterios propios del contexto.

El contrafactual es relevante para los actores que observan en el sentido de decir: aun cuando la acción $a$ en el contexto $o$ no sea observada ni considerada por nosotros es, digamos irracional, según criterios nuestros, los cuales sin embargo, precisamente en tanto que son 'universales' podemos suponer, imaginar, como si estuviera fuera de nuestro contexto, y también fuera del contexto $c$.

¿Es esto importante o tiene alguna consecuencia ventajosa para los actores observadores? Creo que es importante en la medida en que permite creencias y acciones socialmente significativas al interior de su propio sistema sociocultural. Por ejemplo, se puede justificar el promover la expansión de un sistema de acciones y creencias científico, y confrontarlo con sistemas mágicos y religiosos, con relación a un estado de cosas deseable, aunque quizá no es realizable en un futuro previsible y en ese sentido es utópico. Claro está que al respecto entran en juego sistemas valorativos. No es obvio, por ejemplo, que un sistema racional sea preferible a otros. Cierto, bajo determinados principios morales y políticos puede pensarse que un sistema social predominantemente científico y racional es preferible a uno mágico o religioso. Lo que me interesa destacar es que, por un lado, la opción quedaría en buena medida determinada por valores previamente internalizados, y que, por otro, su defensa requiere el uso de contrafactuales.

Parecería que nuestras sociedades industrializadas están en una posición privilegiada para producir y sostener contrafactuales de ese estilo. Obviamente esto es tema para una larga investigación. Por ahora sugeriría simplemente que las complejidades de los sistemas de las sociedades industrializadas son tales que permiten la coexistencia de universos simbólicos alternativos, lo cual favorece la disensión. Pero aun así, la construcción de esos contrafactuales es posible en nuestro medio gracias a sus propios recursos culturales. Por tanto, todo esto sigue siendo rela-

27 Es importante para los observadores, y no para el contexto observado, en el sentido de que son los primeros los interesados en defender la objetividad de la atribución. Claro está que puede ser importante dentro de un contexto, por ejemplo, cuando se quiere defender la verdad, la corrección y la objetividad de un análisis del mismo contexto. Esta es la situación que planteo enseguida para nuestras complejas sociedades. 
tivo a nuestro contexto. Pero éste es ya tan complejo, y permite en todo caso, por ejemplo, la formulación de utopías que pueden ser decisivas en procesos de cambio social y de liberación, que la forma de relativismo a la que me he comprometido es, a mi juicio, inofensiva, en tanto que no es incompatible con la construcción de utopías y el papel de éstas en teorías de la liberación. 